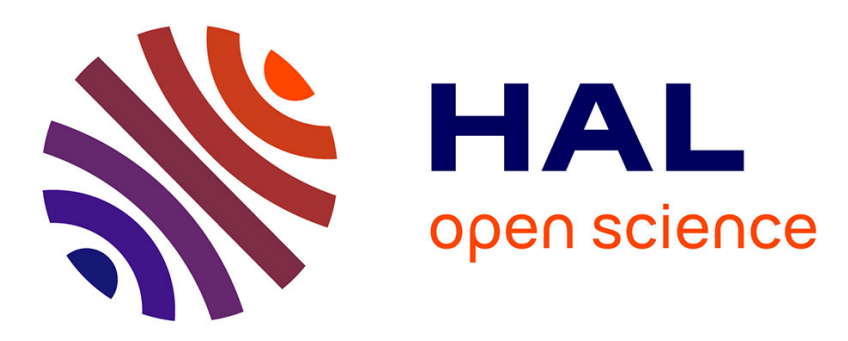

\title{
Discrete Relaxation Oscillation Frequency Hopping in Delayed-feedback Semiconductor Lasers
}

A.V. Kovalev, P.A. Dmitriev, B. Tykalewicz, D. Goulding, B. Kelleher, M.J. Wishon, A. Locquet, E.A. Viktorov

\section{- To cite this version:}

A.V. Kovalev, P.A. Dmitriev, B. Tykalewicz, D. Goulding, B. Kelleher, et al.. Discrete Relaxation Oscillation Frequency Hopping in Delayed-feedback Semiconductor Lasers. 2018 International Conference Laser Optics (ICLO), Jun 2018, St. Petersburg, Russia. pp.144-144, 10.1109/LO.2018.8435693 . hal-03084760

\section{HAL Id: hal-03084760 https://hal.science/hal-03084760}

Submitted on 21 Dec 2020

HAL is a multi-disciplinary open access archive for the deposit and dissemination of scientific research documents, whether they are published or not. The documents may come from teaching and research institutions in France or abroad, or from public or private research centers.
L'archive ouverte pluridisciplinaire HAL, est destinée au dépôt et à la diffusion de documents scientifiques de niveau recherche, publiés ou non, émanant des établissements d'enseignement et de recherche français ou étrangers, des laboratoires publics ou privés. 


\title{
Discrete Relaxation Oscillation Frequency Hopping in Delayed-feedback Semiconductor Lasers
}

\author{
A.V. Kovalev ${ }^{1}$, P.A. Dmitriev ${ }^{1}$, B. Tykalewicz ${ }^{2,3}$, D. Goulding, ${ }^{2,3}$, B. Kelleher ${ }^{3,4}$, M.J. Wishon, ${ }^{5,6}$, A. Locquet ${ }^{5,6}$, E.A. \\ Viktorov ${ }^{1}$ \\ ${ }^{1}$ ITMO University, St. Petersburg, Russia \\ ${ }^{2}$ Cork Institute of Technology, Cork, Ireland \\ ${ }^{3}$ Tyndall National Institute, Univ. College Cork, Cork, Ireland \\ ${ }^{4}$ University College Cork, Cork, Ireland \\ ${ }^{5}$ Georgia Tech-CNRS UMI 2958, Georgia Tech Lorraine, Metz, France \\ ${ }^{6}$ School of Electrical and Computer Engineering, Georgia Institute of Technology, Atlanta, USA
}

\begin{abstract}
We study the dynamics of semiconductor lasers subject to strong delayed optical feedback. We find that the discrete nature of the external-cavity modes leads to a discrete set of relaxation oscillation frequencies observed at the onset of the first instability as the pump current is increased. This explains experimentally observed hops between the frequencies.
\end{abstract}

Keywords - laser diodes with feedback, relaxation oscillations

\section{INTRODUCTION}

Free running laser dynamics is largely determined by two timescales: the cavity repetition rate and the relaxation oscillation frequency. The laser cavity forms a discrete set of optical modes while the relaxation oscillation frequency gradually changes with the pump current with a square-root dependence. In a delayed feedback configuration, the external cavity adds a third timescale, that of the external cavity repetition rate. We show that for lasers with highly damped relaxation oscillations, the external cavity repetition rate can be resonant with the relaxation oscillations leading to $a$ discretization of the relaxation oscillation frequency.

\section{EXPERIMENTAL RESULTS AND DISCUSSION}

Experimentally, the solitary laser (either a multi-quantum well or quantum dot based device) operates in a stable single mode regime with a side mode suppression ratio of greater than $40 \mathrm{~dB}$. The external cavity is $30-60 \mathrm{~cm}$ long and the feedback strength is adjusted using a variable neutral density optical filter. A supercritical Hopf bifurcation manifests itself via a small amplitude, almost harmonic, intensity time series. The Hopf frequency evolves with the current in a series of discrete nearly constant plateaus. The flat regions are separated by sharp steps, with a step-height corresponding to the external cavity round trip frequency. The Hopf frequency is observed to jump up or down from one step to the next.

We model the laser dynamics using a delay differential equation system with two time delays determined by the laser cavity round trip time and external cavity round trip time [1].
The numerical parameters were chosen in order to match the experimental relaxation oscillation frequency and the external cavity roundtrip time.

Four key features determine the Hopf bifurcation structure: strongly damped relaxation oscillations (characteristic of the studied devices), a long external cavity, a large feedback strength and a small bandwidth of the short laser cavity, matching the condition of single mode operation.

The Hopf bifurcation diagram consists of a number of branches with different frequencies. The number of different Hopf bifurcations depends on the phase-amplitude coupling in the active medium. With increasing feedback strength, two Hopf bifurcations corresponding to different branches come closer and closer and, finally, merge at a cusp bifurcation point. In this case a double Hopf bifurcation point occurs. With only one exception, the Hopf frequency hardly changes along any branch before undergoing a hop. The one exception is the first branch, which starts at the threshold feedback strength for the appearance of any instability. While there is no strict mathematical resonance at the double Hopf points, the difference between frequencies remains almost constant and is close to the external cavity frequency.

Depending on the parameters, the Hopf bifurcation branches may either intersect once or twice. In the former case, the Hopf frequency is in resonance with external-cavity mode frequencies, showing a staircase like dependence [1]. A dual intersection of the Hopf bifurcation branches allows a return to the lower branch with the pump current increase. This explains the hop to the lower dominant relaxation oscillation frequency observed experimentally. The Hopf frequency remains in resonance with the external-cavity modes but the staircase like dependence becomes A-framed.

\section{REFERENCES}

[1] B. Kelleher, M. J. Wishon, A. Locquet, D. Goulding, B. Tykalewicz, G. Huyet, and E. A. Viktorov, "Delay induced high order locking effects in semiconductor lasers,” Chaos 27, 114325 (2017). 